\title{
Epistemologi dan Falsafah berkaitan Terapi Muzik dari Perspektif Cendekiawan Muslim
}

\author{
Epistemology and Philosophy related to Music Therapy from the Muslim Scholars' \\ Perspective
}

\author{
ROZIAH SIDIK@MAT SIDEK, *AZMUL FAHIMI KAMARUZAMAN \& \\ MOHD JAILANI ABDULAH ${ }^{1}$
}

\begin{abstract}
This article studies the comparative analysis of epistemology and philosophy of music in the Islamic civilization according to the viewpoints of medieval scholars in the Islamic civilization. The scholars selected are al-Kindi, Ikhwan al-Safa, al-Farabi and Ibn Sina. The basis of this research begins from the polemic among scholars concerning the legal status of using music, whether permissible or forbidden, due to the absence of authenticated textual proof (nas qat'i) from al-Quran and protracted debate over the authenticity of hadith on the prohibition of music. Behind the debate is that music was applied as an Islamic psychotherapy method of treatment in hospitals of the medieval Islamic civilization such as Fez Hospital in Morocco, ${ }^{c}$ Adudi Hospital in Baghdad, al-Mansuri Hospital in Cairo, Nuri Hospital in Damascus, al-Arghuni Hospital in Allepo, Gevher Nesibe Hospital and Giyaseddin Keyhusrev Medical Hospital in Kayseri, Keykavus Hospital in Sivas, Turan Malik Hospital in Divrighi, Pervane Bey Hospital in Tokat, Atabey Ferruh Hospital in Cankiri, Ali bin Pervane Hospital in Kastamonu, Amasya Hospital in Amasya, Fatih Hospital in Istanbul, Edirne Sultan Bayezid II Hospital in Edirne and Suleymaniye Hospital in Istanbul. This research uses qualitative methodology and library research method by analyzing various primary and secondary sources. Research results show that there is a slight discrepancy of views between supporters of neo-Pythagorean (al-Kindi and Ikhwan al-Safa) and Aristotelian (al-Farabi and Ibn Sina) schools of thought from the epistemological viewpoint. However, in terms of philosophy, there seems to be points of similarity in the matter of enhancement of moral and spiritual values for the sake of human well-being, whether physical or spiritual.
\end{abstract}

Keywords: Music therapy, Islamic Civilization, Epistemology of music, Philosophy of music.

Berdasarkan catatan sejarah, muzik sudah sekian lama menjadi polemik dalam kalangan para ulama berhubung dengan status hukum sama ada harus atau haram disebabkan oleh ketiadaan nas yang qat'i daripada al-Quran dan perdebatan yang berpanjangan mengenai kesahihan hadis

${ }^{1}$ Roziah Sidek@Mat Sidek*, Ph.D. (corresponding author), Assoc. Prof. at Research Centre for Arabic Language and Islamic Civilization, Faculty of Islamic Studies, Universiti Kebangsaan Malaysia, 43600 BANGI, Malaysia. Email: roziah@ukm.edu.my; Azmul Fahimi Kamruzaman, Ph. D. Senior Lecturer at Research Centre for Arabic Language and Islamic Civilization, Faculty of Islamic Studies, Universiti Kebangsaan Malaysia, 43600 BANGI, Malaysia. Email: azmul@ukm.edu.my; Mohd Jailani Abdullah, Ph. D. Student, at Research Centre for Arabic Language and Islamic Civilization, Faculty of Islamic Studies, Universiti Kebangsaan Malaysia, 43600 BANGI, Malaysia. Email: jai_amanee@yahoo.com.my

$$
\text { https://doi.org/10.24035/ijit.19.2021.201 }
$$


mengenai larangan muzik. Ironinya, muzik diaplikasikan sebagai salah satu kaedah rawatan psikoterapi Islam di hospital-hospital abad pertengahan tamadun Islam seperti Hospital Fez di Morroco, Hospital cAdudi di Baghdad, Hospital al-Mansuri di Kaherah, Hospital Nuri di Damshiq, Hospital al-Arghuni di Allepo, Hospital Gevher Nesibe dan Sekolah Perubatan Giyaseddin Keyhusrev di Kayseri, Hospital Keykavus di Sivas, Hospital Turan Malik di Divrighi, Hospital Pervane Bey di Tokat, Hospital Atabey Ferruh di Cankiri, Hospital Ali bin Pervane di Kastamonu, Hospital Amasya di Amasya, Hospital Fatih di Istanbul, Hospital Edirne Sultan Bayezid II di Edirne, Hospital Suleymaniye di Istanbul dan lain-lain lagi. Persoalannya, wajarkah ia dianggap sebagai rawatan psikoterapi Islam dan apakah justifikasinya. Bagi menjawab persoalan ini kami mengkaji epistemologi dan falsafah muzik dari perspektif pemikiran sarjana tamadun Islam abad pertengahan iaitu al-Kindi (wafat $260 \mathrm{H} / 873 \mathrm{M}$ ), Ikhwan al-Safa (abad ke-4 H/10 M), al-Farabi (wafat 339 H/950 M) dan Ibn Sina (wafat 429 H/1037 M).

Epistemologi merujuk kepada teori tentang pengetahuan terutamanya yang berkaitan dengan kajian kritis tentang kesahihan, kaedah dan skop sesuatu pengetahuan. The Concise Columbia Encyclopedia edisi ke-3 (1994) mentakrifkan epistemologi sebagai suatu cabang falsafah yang membincangkan tentang asal-usul dan tabiat pengetahuan. Menurut The Dictionary of Philosophy (1942) pula, epistemologi ialah cabang falsafah yang mengkaji tentang asal-asul, struktur, metode dan kesahan sesuatu pengetahuan. The Cambridge Dictionary of Philosophy (1999) pula menyebut epistemologi sebagai kajian tentang tabiat pengetahuan dan justifikasinya. Secara spesifiknya ia merupakan kajian mengenai ciri-ciri pengetahuan, sumber, skop dan juga justifikasi. Manakala Oxford Dictionary of Sociology (2000) pula mendefinisikan epistemologi sebagai sebuah pemikiran falsafah mengenai teori ilmu dalam konteks bagaimanakah pengetahuan yang kita miliki itu diketahui dan diperolehi.

Beberapa orang sarjana turut memberikan definisi epistemologi. Menurut Blaike (2000), epistemologi ialah cabang falsafah yang menitikberatkan soal teori mengenai ilmu iaitu berkaitan dengan metode, validiti dan sumber bagi sesuatu pengetahuan dalam realiti sosial. Manakala Grix (2002) pula menyatakan, dari segi etimologi, epistemologi berasal daripada bahasa Greek iaitu episteme bermaksud pengetahuan dan logos bermaksud hujah logik. Ini bermakna epistemologi ialah suatu proses untuk memperolehi pengetahuan dan ia memfokuskan kepada pembangunan teori-teori baru. Cara mendapat pengetahun itu tidak bersifat statik dan ia sentiasa berubah di mana kedudukan epistemologikal yang dipilih oleh seseorang penyelidik akan memberi pandangan yang berbeza walaupun fenomena sosial tersebut adalah sama.

Berdasarkan kepada definisi dan pandangan berkaitan epistemologi, kami merumuskan bahawa epistemologi secara leksikal bermaksud teori tentang pengetahuan, terutamanya yang berkaitan dengan kajian kritis tentang kesahihan, kaedah dan skop sesuatu pengetahuan. Manakala falsafah pula ialah pengetahuan tentang pengertian yang dianggap sebagai ilmu yang tertinggi yang menjadi dasar ilmu-ilmu lain. Epistemologi ialah salah satu cabang falsafah yang membahaskan tentang hakikat pengetahuan manusia. Persoalan pokok yang berkembang dalam epistemologi meliputi sumber-sumber pengetahuan, watak dari pengetahuan manusia, kesahihan sesuatu pengetahuan dan bagaimana pengetahuan manusia itu diperoleh. Falsafah pula merupakan prinsip umum yang mendasari sesuatu pengetahuan, kebiasaannya berkaitan dengan nilai-nilai moral. Sehubungan dengan itu, jelas Cozma (2007) sistem nilai moral ataupun etika yang menjadi wacana dalam falsafah muzik berhubungkait dengan kesejahteraan manusia. Ia dianggap sebagai satu usaha manusia untuk berada dalam skop prinsip umum nilai-nilai moral seperti kebijaksanaan, kesederhanaan, keadilan, semangat, kesatuan, perkongsian hidup, kemurahan, simpati, cinta, ketulusan, hormat-menghormati, kebebasan, tugas serta tanggungjawab dan sebagainya. 


\section{Epistemologi dan Falsafah Muzik al-Kindi}

Ilmu muzik pada pandangan al-Kindi ialah 'sains pertengahan' (al-cilm al-awsat). Kedudukannya sebaris dengan ilmu aritmetik, geometri dan astronomi. Kewujudannya adalah sebagai perantara yang menghubungkan antara 'sains bawahan' (sains tabii/semulajadi) dan 'sains atasan' (sains luar tabii/metafizik). Dikatakan 'sains luar tabii' tersebut boleh memberi pengaruh kepada sains tabii. Sains pertengahan ini juga dikenali oleh orang-orang Arab sebagai ilmu matematik. Keempat-empat cabang ilmu matematik iaitu aritmetik, muzik, geometri dan astronomi terangkum di dalam metod pendidikan klasik (quadrivium/al-hikmah al-ruba ìyah) yang diperkenalkan oleh tamadun Greek dan kemudiannya diadaptasikan ke dalam tamadun Islam (Yusof 1962).

Berkaitan dengan pertalian muzik dengan alam tabii serta luar tabii, Shehadi (1995) menganggapnya sebagai teras kepada perbahasan mengenai epistemologi muzik dari perspektif pemikiran al-Kindi. Oleh kerana muzik menjadi penghubung di antara alam fizik dan alam metafizik, maka al-Kindi percaya ketiga-tiga kategori sains tersebut pastinya mempunyai prinsip afiniti (mushakalah) antara satu sama lain dengan alasan bahawa kesemuanya terangkum ke dalam empat jenis unsur iaitu tanah, air, api dan udara termasuk juga unsur astronomi. Ini bermakna alKindi menghubungkaitkan muzik dengan astronomi, astrologi, meteorologi, metafizik dan kosmologi menerusi empat tali al-cud (alat muzik bertali seumpama gambus), lebih-lebih lagi bentuk fizikalnya separa sfera menyamai separa sfera objek-objek samawi.

Prinsip afiniti yang dipegang oleh al-Kindi selari dengan catatan Ibn Hindu (2010) dalam karyanya Miftah al-Tib wa Minhaj al-Tullab mengenai saranan Galen (meninggal tahun $200 \mathrm{M}$ ) khusus untuk para doktor agar mempelajari ilmu astronomi memandangkan kedudukannya sebagai cabang ilmu matematik dan manfaatnya dalam bidang perubatan. Lebih-lebih lagi Hippocrates (meninggal 380 S.M) pernah menyatakan bahawa peranan astronomi dalam perubatan amat ketara sekali dan sepatutnya tidak dipandang remeh. Ini adalah kerana setiap wabak penyakit yang melanda mempunyai perkaitan dengan fenomena astronomi misalnya pembentukan fasa-fasa bulan, posisi bulan berbanding matahari dan fenomena mundur ke belakang (retrograde motion) planet-planet di angkasa. Untuk lebih jelas lagi mengenai prinsip afiniti tersebut, al-Hulwi (1974) memperincikan bahawa tali al-cud iaitu bam, mathna, mathlath/mithlath dan zir mempunyai persamaan dengan empat pusingan waktu, empat buruj, empat planet, empat humor, empat arah angin, empat musim, empat peringkat pertumbuhan gigi atau umur, empat jenis kekuatan mental serta fizikal dan empat jenis tindakan yag terhasil. Rumusan al-Hulwi (1974) menunjukkan bahawa perbincangan tuntas al-Kindi mengenai muzik jelas menggambarkan bahawa muzik bukan hanya semata-mata hiburan (tatrib wa tanghim), malah ia juga merupakan medium terapi (cilajiyyah) dan nutrisi (ghidha'iyyah) untuk tubuh badan serta sumber kebahagiaan hidup manusia merentasi sempadan masa dan tempat.

Dalam konteks falsafah muzik, al-Kindi menyakini muzik mempunyai kesan terapeutik yang amat luar biasa. Sehubungan dengan itu, al-Kholy (1984) dan Farmer (1997) menjelaskan terdapat tiga jenis gubahan melodi yang dianggap al-Kindi bersesuaian dengan mood seseorang iaitu al-basti (ekstrovert/keriangan), al-qabdi (introvert/kesedihan) dan al-muctadil (moderate/ketenangan). Begitu juga dengan irama, misalnya irama perlahan dan berat bersesuaian dengan seseorang yang sedang dilanda kesedihan atau mengalami gejala melankolia. Manakala irama cepat dan ringan pula bersesuaian dengan suasana keriangan dan kegembiraan. Menurut Yusuf (1962) dan Farmer (1997), antara jenis-jenis irama yang seringkali digunakan dalam sesi terapi ialah al-makhuri, thaqil al-awwal, thaqil al-thani, thaqil al-mumtad, al-hazaj, al-ramal dan al-khafif. Al-makhuri ialah irama yang boleh merangsang kekuatan rohani. Thaqil al-awwal dan thaqil al-thani pula ialah irama yang boleh mencetuskan sikap kemuliaan, kemurahan hati dan keterbukaan. Thaqil al-mumtad pula merujuk kepada irama yang menghasilkan kesayuan. Manakala al-hazaj, al-ramal dan al-khafif pula ialah irama yang boleh mencetuskan mencetuskan keheningan, kegembiraan dan keriangan. Setiap 
irama tersebut sewajarnya disesuaikan dengan waktu tertentu misalnya pada permulaan siang digunakan irama thaqil al-awwal dan al-thani. Pada pertengahan hari digunakan irama al-makhuri. Pada penghujung hari digunakan irama al-hazaj, al-ramal dan al-khafif, manakala pada waktu tidur pula digunakan irama thaqil al-mumtad.

Setiap irama tersebut juga mempunyai kaitan dengan empat jenis tali al-cud dan empat jenis humor. Empat jenis tali al-'ud ialah al-zir, al-mathna, al-mathlath dan al-bam. Manakala empat jenis humor pula ialah hempedu kuning, darah, lendir dan hempedu hitam.

Berdasarkan laporan al-Hulwi (1974) dan Farmer (1997), tali al-zir (mencetuskan kegembiraan, kemuliaan, kemenangan, kecekalan, keberanian dan sebagainya) bersesuaian dengan al-makhuri. Kesan terapeutiknya ialah dapat menguatkan cairan hempedu kuning dan menggerakkannya, menenangkan cairan balgham serta menghilangkannya. Tali al-mathna (mencetuskan kegembiraan, keriangan, kemurahan hati, kemuliaan, kasihan belas, kelembutan dan seumpamanya) pula berseseuaian dengan irama thaqil al-awwal dan al-thani. Ia dapat menguatkan darah dan menggerakkannya, menenangkan cairan hempedu hitam serta menghilangkannya. Tali al-mathlath/al-mithlath (mencetuskan kesedihan, kehibaan dan seumpamanya) bersesuaian dengan thaqil al-mumtad. Ia dapat menguatkan balgham dan menggerakkannya, menenangkan cairan hempedu kuning serta menghilangkannya. Tali al-bam (mencetuskan kegembiraan, toleransi, kasih sayang dan seumpamanya) bersesuaian dengan al-hazaj, al-ramal dan al-khafif. Ia dapat menguatkan cairan hempedu hitam dan menggerakkannya, menenangkan darah serta menghilangkannya. Secara realitinya, menurut Ibn al-Qifti (1903) dan Shehadi (1995), al-Kindi pernah mengaplikasi terapi muzik ke atas pesakit apoplexy (saktah faj'ah).

\section{Epistemologi dan Falsafah muzik Ikhwan al-Safa}

Perbincangan Ikhwan al-Safa mengenai epistemologi terapi muzik bermula dengan memberi definisi muzik secara etimologi. Jelas Ikhwan al-Safa seperti yang dicatatkan oleh 'Abd Allah (1887), al-musiqa bermaksud nyanyian, al-musiqar ialah penyanyi dan al-musiqat pula ialah instrumen muzik yang mengiringi nyanyian. Al-musiqa terhasil daripada getaran bunyi, kemudian bunyi tersebut disusun mengikut pola-pola tertentu bagi membentuk pelbagai jenis nada. Seterusnya nada itu pula akan digubah dengan sistematik sehingga menjadi sebuah alunan melodi yang indah dan enak didengari. Seterusnya Ikhwan al-Safa cuba mengupas berkaitan suara atau bunyi yang merupakan asal-usul terbentuknya irama dan melodi. Kupasan mereka mengenai bunyi membuktikan kumpulan sarjana ini juga mempunyai pengetahuan yang luas di dalam bidang fizik.

Sehubungan dengan doktrin muzik samawi (the harmony of the spheres) pula, nampaknya Ikhwan al-Safa mempunyai sudut pandang yang sama dengan al-Kindi iaitu putaran planet-planet menghasilkan bunyi yang merdu seumpama bunyi instrumen muzik. Tegas Ikhwan al-Safa ('Abd Allah1887) pergerakan objek-objek samawi (al-harakat al-aflak wa al-kawakib) menghasilkan irama yang paling lunak dan melodi yang paling merdu kerana kedudukannya dalam nisbah (ratio) atau ukuran tertentu dan pergerakannnya mengorbit matahari amat teratur sekali sehingga menghasilkan muzik yang sempurna.

Pada hemat kami, perbincangan tuntas Ikhwan al-Safa mengenai bunyi jelas menunjukkan bahawa muzik bukan sahaja terbentuk daripada instrumen semata-mata, bahkan juga terbit daripada suara manusia, binatang dan juga alam semulajadi misalnya bunyi aliran air. Ini bermakna epistemologi muzik pada pemikiran Ikhwan al-Safa mempunyai skop yang luas merangkumi keseluruhan komponen alam semesta sama ada makhluk bernyawa ataupun tidak bernyawa asalkan mempunyai irama dan melodi. Inilah juga yang disebut oleh al-Ghazali (2011) apabila menjelaskan dua sumber utama muzik iaitu benda yang tidak benyawa (seperti seruling, gitar dan gendang) dan kerongkong makhluk bernyawa (iaitu manusia dan haiwan). 
Falsafah muzik dari perspektif pemikiran Ikhwan al-Safa pula terserlah menerusi perbahasan mereka mengenai muzik sebagai alat untuk mendidik jiwa, memupuk akhlak yang mulia serta nilai-nilai moral yang tinggi dan juga agen terapeutik. Menurut Ikhwan al-Safa ('Abd Allah 1887), muzik dapat memberi kekuatan fizikal bagi individu yang sering melakukan kerjakerja berat dan memenatkan. Ia juga dapat menaikkan semangat keberanian di medan peperangan, mendamaikan pergaduhan, mencetuskan perasaan gembira, sedih dan rasa mengantuk, digunakan di tempat-tempat ibadat seperti alunan bacaan ayat-ayat suci al-Quran semasa solat, memohon doa dan bermunajat sambil menangis. Setiap nada yang merdu menerusi bacaan yang bermelodi tersebut adalah bertujuan untuk melembutkan hati, melahirkan perasaan rendah diri, khusyuk, tunduk serta patuh segala perintah Allah s.w.t dan meninggalkan segala laranganNya, ia juga dapat menimbulkan perasaan menyesal dan ingin bertaubat daripada segala dosa. Muzik turut digunakan di hospital sebagai terapi, begitu juga sebagai medium pendidikan kanak-kanak serta alat komunikasi antara manusia dan haiwan.

\section{Epistemologi dan Falsafah muzik al-Farabi}

Penjelasan al-Farabi mengenai epistemologi muzik sebagaimana yang dinyatakan Shehadi (1995), adalah selari dengan prinsip yang dipegang oleh Aristotle dan Aristoxenus (murid Aristotle) iaitu penolakan terhadap doktrin muzik samawi Pythagoras. Sebaliknya, ia lebih tertumpu kepada fenomena muzik itu sendiri tanpa dikaitkan dengan apa-apa jenis sains seperti geometri, astronomi dan aritmetik. Menurut Farmer (1997), terdapat dua sebab mengapa doktrin muzik samawi Pythagoras ditolak. Pertama, ia ditolak ekoran daripada pengkajian dilakukan ke atas karya Aristotle iaitu De caelo. Kedua, ia ditolak kerana pandangan al-Farabi sendiri mengenai teori bunyi. Mengulas mengenai prinsip muzik Aristotle, jelas al-Kholy (1984), ia berbentuk logikal dan analitikal iaitu meletakkan asas seni muzik dalam platform rasional dan imaginatif (takhayyul). Ini bermakna entiti muzik ini bermula daripada naluri semulajadi manusia (fitrah ghariziyyah) itu sendiri untuk menghasilkan unsur-unsur seni yang rasional. Dengan berpandukan naluri semulajadi tersebut, manusia memperoleh imaginasi dan kekuatan untuk mencipta sebuah melodi yang harmoni. Ini bermakna, setiap gubahan melodi yang dilakukan tiada hubungkait dengan doktrin muzik samawi. Bahkan, al-Farabi (t.th.) menganggap doktrin tersebut tidak benar kerana tidak mungkin pergerakan objek-objek samawi menghasilkan sebarang melodi yang harmoni.

Kami mulakan perbincangan mengenai falsafah muzik dari perspektif pemikiran al-Farabi dengan mengutarakan definisi muzik menurut pandangan beliau. Jelas al-Farabi (t.th.) terma almusiqa bermaksud al-alhan (melodi) dan ia secara khususnya merujuk kepada suara nyanyian (vokal). Manakala secara umumnya pula, ia bermaksud sebarang alunan nada walaupun tidak disertai sebarang lafaz ataupun vokal. Meskipun al-musiqa bermaksud melodi, Shehadi (1995) menjelaskan, ia juga turut merangkumi elemen-elemen lain seumpama tone (kualiti bunyi), jeda (jarak antara dua pic tone), irama dan sebagainya. Ini bermakna melodi pada pandangan al-Farabi adalah rangkuman kumpulan nada tertentu yang disusun dengan teratur sehingga menghasilkan satu set melodi yang merdu. Al-Farabi (t.th.) membahagikan melodi kepada tiga kategori. Kategori pertama ialah al-mulidhdhah iaitu melodi yang memberikan keseronokan dan ketenangan jiwa. Kategori kedua pula ialah al-mukhayyalah iaitu melodi yang membentuk suatu imaginasi dalam pemikiran. Manakala kategori ketiga ialah al-inficaliyyah iaitu melodi yang mempengaruhi emosi serta tingkah laku manusia dan haiwan. Jika ketiga-tiga melodi ini digabungkan bersama, ia akan menghasilkan sebuah melodi yang lebih baik dan sempurna sehingga dapat memberi kesan yang amat efektif terhadap jiwa pendengar. Dari sudut gubahan melodi pula, jelas al-Farabi (t.th.), ia boleh dihasilkan melalui dua cara. Pertama ialah menerusi suara atau vokal manusia. Ia merangkumi pelbagai jenis seperti al-ghina' (nyanyian), al-niyahah (ratapan), qasidah dan bacaan al-Quran dan juga al-huda' (nyanyian penunggang unta). Manakala cara yang kedua ialah menerusi

$$
\text { https://doi.org/10.24035/ijit.19.2021.201 }
$$


peralatan muzik. Pada pandangan al-Farabi (t.th.), melodi yang indah merupakan suatu keperluan semulajadi semua makhluk sama ada manusia ataupun haiwan. Misalnya muzik atau nyanyian yang dimainkan ketika bekerja dapat mengurangkan kepenatan dan sekaligus membangkitkan semangat untuk bekerja lebih kuat. Begitu juga haiwan seumpama unta akan berjalan lebih laju setelah terdengar nyanyian al-huda'.

Dalam konteks al-nagham pula, al-Farabi (t.th.) berpandangan bahawa ia hendaklah berpadanan dengan emosi dan perasaan manusia seperti nada untuk memupuk perasaan kasihsayang, merangsang kekuatan fizikal, mencetuskan kesedihan, menimbulkan ketakutan, membangkitkan keseronokan dan sebagainya. Reaksi daripada nada-nada tersebut berlaku setelah suatu imaginasi dalam pemikiran pendengar terbentuk sehingga dapat menyentuh hati dan perasaan mereka. Sebenarnya nada-nada tersebut, menurut al-Farabi (t.th.), tidak mempunyai nama khusus. Ia hanya diketahui berdasarkan bentuk pengaruhnya terhadap emosi seseorang misalnya, perasaan sedih dikenali sebagai nada al-muhazzin/al-huzni/al-tahzin/al-tahzinat, perasaan kesal dikenali asafi, perasaan murung dikenali jazaci, perasaan seronok dikenali $\mathrm{mu}^{c} a z z i / m u s a l l i$, perasaan kasih sayang dikenali muhabbib, perasaan marah dikenali baghdi, perasaan kasihan belas dikenali rahmi, perasaan takut dikenali mukhawwif dan sebagainya. Walau bagaimanapun, secara umumnya nada yang boleh mempengaruhi emosi pendengar boleh diklasifikasikan kepada tiga jenis. Jenis pertama ialah nada yang membangkitkan kekuatan jati diri (quwwah al-nafs) seperti semangat penentangan (al-cadawah), kemarahan (al-ghadab), ketegasan (al-tahawwur) dan sebagainya. Jenis kedua ialah nada yang melemahkan jati diri seperti ketakutan (al-khawf), kasihan (al-rahmah), kesedihan (al-jazac) dan sebagainya. Manakala jenis ketiga ialah nada pertengahan (al-tawassut) antara kekuatan dan kelemahan. Rangkuman kesemua nada tersebut pula, tegas al-Farabi (t.th.), akan menghasilkan sebuah melodi yang sempurna, iaitu melodi al-maqwiyyah (kekuatan kendiri), al-mulayyinah (kelemahan kendiri) dan al-mucaddilah atau alistiqrariyyah (pertengahan antara al-maqwiyyah dan al-mulayyinah).

\section{Epistemologi dan Falsafah muzik Ibn Sina}

Perbincangan Ibn Sina mengenai epistemologi dan falsafah muzik secara terperinci termuat di dalam dua buah karyanya yang terkenal iaitu Kitab al-Shifa' dan al-Najah. Kitab al-Shifa' mengandungi 18 jilid manakala al-Najah pula mengandungi tiga jilid (Yusof 1956; Ibn Abi Usaybicah 1965). Perbahasan Ibn Sina tentang muzik diasaskan kepada disiplin matematik dan juga sains tabii. Menurut Farrukh (1970), Ibn Sina menjelaskan muzik sebagai suatu ilmu untuk mengenali jenis-jenis nada, kaedah menggubah melodi dan cara bermain peralatan muzik. Dalam karyanya sendiri pula, Ibn Sina seperti yang dicatatkan oleh al-Danawi (1999: 9) mendefinisikan muzik sebagai:

Disiplin ilmu matematik yang membicarakan soal nada (al-nagham) dari aspek konsonan (almuttafiq) dan disonan (al-mutanafir) serta jeda bagi mengetahui bentuk gubahan sesuatu melodi. Skop perbahasan tentang muzik ini merangkumi dua kategori iaitu: a) mengenai keadaan nada muzik itu sendiri. Ia dibincang khusus dalam bab al-ta'lif (gubahan melodi) dan b) mengenai jeda (jarak waktu antara dua bunyi) dan ia pula dibincang dalam bab cilm al-iqac (ritma). Kedua-dua kategori perbincangan tersebut merentasi sempadan lain-lain disiplin ilmu iaitu aritmetik, sains tabii dan sebahagian kecil geometri.

Ibn Sina bukan sahaja melihat muzik dalam dimensi komposisi melodi semata-mata tetapi turut membahas muzik dalam konteks nilai moral dan etika. Sehubungan dengan itu, Farmer (1997: 310) memetik kata-kata Ibn Sina sebagaimana berikut: 
Apabila sesuatu bunyi itu dihiasi dengan gubahan melodi yang harmoni, pastinya akan memberi kesan yang mendalam kepada jiwa manusia. Lazimnya pada permulaan, sesuatu melodi itu akan dimainkan dengan not yang rendah kemudian beransur-ansur meningkat kepada not yang tinggi dan begitulah seterusnya silih berganti. Dengan gubahan yang sedemikian, pastinya akan menyebabkan jiwa manusia itu tersentuh dan terusik. Ini bermakna, setiap perubahan daripada satu not kepada satu not yang lain akan memberi kesan yang berbeza terhadap jiwa dan emosi manusia misalnya jiwa yang lemah akan menjadi kuat dan sebaliknya.

Rangkuman daripada definisi muzik dan juga sudut pandang Ibn Sina terhadap nilai moral yang tersirat di sebalik melodi, menggambarkan bahawa entiti muzik bukan hanya menitikberatkan soal estetika semata-mata tetapi juga soal etika dan moral.

Epistemologi muzik dari perspektif pemikiran Ibn Sina menjurus kepada skop suara ataupun bunyi (al-sawt). Menurut Ibn Sina (al-Danawi 1999), suara atau bunyi yang terhasil kadangkala enak didengar dan kadangkala sebaliknya disebabkan oleh intensiti dan kualiti suara tersebut. Ini bermakna bunyi yang didengari itu sama ada enak atau sebaliknya bergantung kepada dua keadaan. Keadaan pertama ialah al-Hikayah (keserasian dengan emosi manusia). Manakala keadaan kedua pula ialah al-ta'lif (jenis gubahan sama ada harmoni atau sumbang). Kedua-dua keadaan tersebut akan dirasai kesannya menerusi kekuatan intuisi (daya atau kebolehan memahami (mengetahui, merasai) sesuatu tanpa berfikir atau membuat pertimbangan secara sedar, gerak hati) yang wujud pada manusia dan haiwan. Bunyi adalah suatu mekanisme yang boleh menarik minat haiwan dalam spesis yang sama bagi tujuan pembiakan, meminta pertolongan (panggilan si anak) dan juga sebagai amaran daripada sebarang ancaman. Manakala manusia pula menggunakan suara untuk meluahkan perasaannya dan juga mengetahui apa yang tersemat dalam sanubari orang lain. Dengan demikian mereka dapat berkongsi kehidupan ini tanpa sebarang halangan. Suara-suara ini, sama ada suara manusia ataupun binatang (selain daripada suara burung) tidak boleh dianggap muzik kerana tidak wujud unsur-unsur muzikal, melainkan jika ia digubah dengan merdu dan berdasarkan suatu sistem yang teratur misalnya syair. Tambahan pula gubahan tersebut serasi dengan kualiti temperamen manusia, maka pada saat itu suara tersebut pastinya akan menyentuh perasaan.

Berkaitan dengan perbincangan Ibn Sina mengenai suara, kami mendapati pendekatannya berbeza dengan Ikhwan al-Safa kerana ia lebih tertumpu kepada dimensi biologi berbanding dengan dimensi fizik. Pada pandangan Ibn Sina, dari segi biologinya suara dijadikan alat untuk kelangsungan hidup spesis haiwan menerusi interaksi antara si jantan dan si betina. Malah, suara juga dilihat sebagai medium sosial dalam kalangan komuniti manusia untuk tujuan komunikasi dan berkongsi perasaan dalam pelbagai aspek kehidupan. Di antara suara-suara ini, hanya suara burung sahaja yang dianggap mempunyai unsur muzik seumpama pitching (peletakan sesuatu bunyi dan muzik), manakala suara-suara lain adalah sebaliknya. Namun begitu, suara tersebut khususnya suara manusia boleh digubah menjadi suara yang bermelodi dan berirama serta harmoni. al-Kholy (1984) pula menggambarkan perbincangan Ibn Sina berkaitan suara adalah persis perbincangan Darwin dalam teori evolusinya, meskipun tidak secara menyeluruh. Ini bermakna muzik menurut Ibn Sina membantu proses perkembangan atau evolusi spesis haiwan secara semulajadi. Bahkan, manusia sama ada lelaki ataupun wanita, dianggap spesis pertama yang menggunakan nada muzik untuk memikat hati pasangan masing-masing.

Rentetan daripada penjelasan epistemologi muzik secara naturalistik, Ibn Sina (al-Danawi 1999) dengan tegas menolak sebarang pertalian antara objek samawi (al-ashkal al-sama'iyyah) dengan sifat peribadi manusia (al-akhlak al-nafsaniyyah), begitu juga nisbah jeda muzik dengan kedudukan planet-planet di angkasa. Ini adalah kerana, menggabungkan kesemua cabang ilmu matematik iaitu aritmetik, muzik, astronomi dan geometri dalam rangka memahami falsafah muzik adalah suatu kesilapan. Senario ini berlaku akibat kegagalan memahami secara mendalam perbezaan antara setiap cabang ilmu matematik tersebut. Doktrin yang diwarisi daripada ahli

$$
\text { https://doi.org/10.24035/ijit.19.2021.201 }
$$


falsafah silam ini (merujuk kepada ahli falsafah Greek), telah diterima pakai sepenuhnya oleh segelintir sarjana tamadun Islam tanpa diselidiki terlebih dahulu sejauhmanakah kesahihannya (merujuk kepada al-Kindi dan Ikhwan al-Safa). Selain daripada penolakan terhadap doktrin The harmony of the spheres tersebut, Ibn Sina juga tidak pernah menyebut dalam karyanya bahawa Banu Lamak adalah individu yang pertama bermain $a l^{-c} u d$ dan juga mencipta beberapa jenis peralatan muzik dengan alasan tiada fakta sejarah yang dapat membuktikan kesahihannya sebagaimana yang simpulkan oleh al-Hifni dalam prakata Kitab al-Shifa'. Pada pandangan penulis, ini menunjukkan bahawa Ibn Sina mementingkan soal kewarasan berfikir yang disertakan dengan bukti-bukti yang jelas dan rasional.

Dalam hal tersebut juga, Shiloah (1995) turut merumuskan bahawa Ibn Sina bukan sahaja menolak sebarang pertalian antara muzik dengan astrologi dan kosmologi, bahkan juga menganggapnya sebagai sesuatu yang tidak munasabah. Sebaliknya, Ibn Sina amat meyakini wujudnya hubungan yang erat di antara entiti muzik dan perubatan. Hakikat ini terbukti bahawa alunan muzik dapat mempengaruhi pola denyutan nadi seseorang dan ia merupakan petunjuk utama untuk mengenalpasti tahap kesihatan seseorang. Menurut Ibn Sina (al-Danawi 1999) gubahan suara yang harmoni mampu menghilangkan perasaan sedih serta melegakan sebarang kesakitan. Sehubungan dengan itu, keserasian nada dengan tabiat semulajadi manusia perlu diberi penekanan yang sewajarnya bagi memastikan keberkesanan muzik di dalam merawat pesakit. Setiap jenis nada sememangnya memberi kesan yang berlainan terhadap jiwa pendengar misalnya nada yang rendah dapat memberi ketenangan jiwa, mendamaikan sebarang pertelingkahan dan melahirkan perasaan simpati. Manakala nada yang tinggi serta pantas dapat merangsang semangat dan keberanian.

Perbincangan di atas menunjukkan para sarjana tamadun Islam membahaskan ilmu muzik dalam dua aspek penting iaitu epistemologi dan juga falsafah. Dari aspek epistemologi muzik, kami mendapati bahawa terdapat sedikit percanggahan pandangan antara al-Kindi dan Ikhwan al-Safa dengan al-Farabi dan Ibn Sina. Al-Kindi dan Ikhwan al-Safa lebih cenderung kepada aliran pemikiran neo-Pythagorean. Mereka berpegang kepada penjelasan mistik iaitu doktrin keharmonian muzik objek samawi (Yusuf 1962). Doktrin ini tercetus hasil daripada pengalaman mistik Pythagoras yang kemudiannya dikembangkan oleh para pengikutnya (Pythagorean) sehingga terbentuk sebuah gagasan yang melihat muzik dalam dimensi baru iaitu sebagai agen terapeutik. Antara pengikut Pythagoras ialah Iamblichos, Porphyry, Proklos dan Nicomachus (Farmer 1997). Menurut gagasan ini, gubahan sesuatu melodi muzik itu seharusnya menyamai keharmonian muzik samawi, barulah dapat memberi kesan terapeutik kepada pendengarnya. Persamaan tersebut ialah merujuk kepada sejauhmana gubahan melodi tersebut mampu mengubah temperamen (sifat batin yang mempengaruhi kelakuan seseorang) manusia. Jika gubahan muzik itu memberi kesan positif kepada temperamen manusia, maka ia dianggap telah menyamai keharmonian muzik samawi. Doktrin ini telah menjadi asas kepada pembentukan sebuah gagasan terapi muzik yang menekankan prinsip keharmonian sejagat merangkumi alam samawi dan juga alam manusiawi.

Al-Farabi dan Ibn Sina pula lebih cenderung kepada aliran pemikiran Aristotle. Mereka cenderung kepada penjelasan secara naturalisitik serta pemikiran yang logik iaitu muzik ialah kreativiti yang terhasil daripada naluri semulajadi manusia. Menerusi doktrin ini para ahli perubatan percaya bahawa unsur humor iaitu darah, hempedu kuning, hempedu hitam dan lendir mewakili empat unsur alam iaitu tanah, air, api dan udara. Setiap unsur humor dan alam ini mempunyai sifatnya yang tersendiri iaitu panas, sejuk, kering dan lembap. Lazimnya, setiap unsur tersebut akan menghasilkan sifat yang berpasangan misalnya api atau hempedu kuning bersifat panas dan kering, tanah atau hempedu hitam bersifat sejuk dan kering. Air atau lendir pula bersifat sejuk dan lembap. Manakala udara atau darah bersifat panas dan lembap. Keseimbangan kualiti 
unsur-unsur humor ini bukan sahaja menentukan tahap kesihatan manusia, malah juga menentukan situasi temperamen mereka seperti optimistik, pemarah, murung dan tenang.

Namun dari aspek falsafahnya, ternyata wujud titik persamaan dalam soal peningkatan nilai moral dan spiritual demi kesejahteraan hidup manusia sama ada jasmani ataupun rohani. Sebenarnya perbezaan pandangan mengenai epistemologi muzik tersebut memberi gambaran bahawa konsep muzik ini bukan hanya terhad kepada kajian mengenai irama dan melodi, tetapi pada masa yang sama muzik mempunyai peranan yang lebih penting daripada sekadar hiburan khususnya sebagai agen terapeutik. Ini bermakna setiap melodi yang digubah lebih menjurus kepada tujuan terapi berbanding daripada menjadi halwa telinga semata-mata. Bahkan, setiap gubahan melodi itu juga seharusnya bersesuaian dengan masa-masa tertentu agar kesan terapeutik menjadi lebih optimum. Oleh itu, falsafah terapi muzik adalah bertujuan untuk mewujudkan kestabilan emosi, rohani dan mentaliti agar dapat diharmonikan dengan sikap, tingkahlaku serta tindakan. Terapi muzik cuba mempengaruhi pendengar agar mereka dapat membentuk suatu sistem nilai yang positif di dalam segala aspek kehidupan yang mencakupi jasmani, rohani, emosi dan intelek. Kesihatan jasmani seseorang adalah berkait rapat dengan kesihatan rohani, kestabilan emosi dan kewarasan berfikir.

Berdasarkan perbincangan di atas juga, kami mendapati bahawa muzik wajar dianggap sebagai medium rawatan psikoterapi Islam memandangkan tujuan serta matlamatnya untuk kesejahteraan hidup manusia sama ada dari aspek fizikal, mental, emosi mahupun rohani. Oleh kerana Islam adalah al-Din untuk kesejahteraan dan kebahagiaan hidup insan sejagat, maka terapi muzik menjadi salah satu daripada mekanisme untuk mencapai matlamat tersebut. Dengan demikian misi dan visi perjuangan junjungan besar Nabi kita Muhammad s.a.w yang membawa obor Islam sebagai agama rahmat untuk sekalian alam (rahmatan li al-alamin) dapat direalisasikan.

Epistemologi muzik sebagaimana yang difahami oleh para sarjana tamadun Islam tertumpu kepada aspek sains berbanding dengan hanya semata-mata media hiburan. Manakala falsafah muzik pula adalah berkait rapat dengan aspek moral dan etika manusia. Ini bermakna muzik dilihat berkesan sebagai pencetus motivasi agar rajin bekerja, semangat patriotik para tentera di medan peperangan, membangkitkan rasa cinta dan rindu kepada Ilahi, mendamaikan pertelagahan, merangsang minat untuk melakukan aktiviti yang berfaedah dan yang paling utama ialah sebagai alat rawatan terapi fizikal, mental dan emosi. Justeru itu, tidak hairanlah terapi muzik diaplikasikan secara intensif dan juga ekstensif di hospital-hospital abad pertengahan tamadun Islam sebagai rawatan psikoterapi Islam.

Epistemologi terapi muzik sudah sekian lama dibangunkan oleh tokoh-tokoh ilmuwan abad pertengahan Islam seperti al-Kindi, Ikhwan al-Safa, al-Farabi dan Ibn Sina. Secara keseluruhannya, kami merumuskan bahawa perbahasan mereka mengenai epistemologi terapi muzik tidak dilakukan secara khusus dan spesifik di dalam karya-karya agung mereka namun ia boleh difahami berdasarkan penelitian kepada pelbagai sumber. Ilmu terapi muzik lahir daripada sebuah kajian epistemologi yang berasaskan fakta ilmiah dan saintifik merentasi pelbagai disiplin ilmu termasuk fizik, metafizik, aritmetik dan biologi. Falsafah terapi muzik mereka pula bukan hanya mengandungi elemen estetika semata-mata, sebaliknya merangkumi prinsip moral dan nilai kerohanian. Ini bermakna pemahaman falsafah terapi muzik telah mendedahkan hakikat muzik sebagai agen terapeutik yang bertujuan untuk menjamin kebahagiaan hidup manusia. Nilai-nilai murni yang terhasil daripada aplikasi terapi muzk dilihat menepati ciri-ciri yang terdapat di dalam ajaran Islam iaitu penekanan terhadap kesempurnaan akhlak dan keperibadian mulia. 


\section{Penghargaan}

Artikel ini adalah output dibawah skim geran penyelidikan FRGS/1/2016/SS105/UKM/02/1

\section{References}

'Abd Allah, Ahmad (pnyt.). 1887. al-Rasa'il Ikhwan al-Safa' wa Khalan al-Wafa'. Bhg. 1.. Bombay: Nakhbat al-Akhbar.

Blaike, N. 2000. Designing Social Research. Cambridge: Polity

Cozma, C. 2007. Ethos of music art- Essay in Moral Philosophy. Romania: Editura 3D Arte.

Al-Danawi, Muhammad Amin (pnyt.). 1999. al-Qanun fi al-Tib. Jil. 1 \& 2. Beirut: Dar al-Kutub al'Ilmiyyah.

al-Farabi, Abu Nasr Muhammad ibn Muhammad ibn Tarkhan. t.th. al-Musiqa al-Kabir. Kaherah: Dar al-Katib al-Arabi li al-Tiba'ah wa al-Nashr.

Farmer, H. G. 1997. The Science of Music in Islam. Jil. 1. Neubauer, E (pnyt.). Frankfurt: Institute for the History of Arabic-Islamic Science.

Farrukh, 'Umar. 1970. Tarikh al-'Ulum 'ind al-'Arab. Bayrut: Dar al-'Ilm li al-Malayin.

al-Ghazali, Abu Hamid Muhammad ibn Muhammad. 2011. Ihya' 'Ulum al-Din. Jeddah: Dar al-Minhaj

Grix, J. 2002. Introducing students to the generic terminology of the social research. Politics 22 (3): 175-186.

al-Hulwi, Salim. 1974. Tarikh al-Musiqa al-Sharqiyyah. Beirut: Dar Maktabah al-Hayah.

Ibn Abi Usaybi'ah, Abu al-'Abbas Ahmad ibn al-Qasim. 1965. 'Uyun al-Anba' fi Tabaqat al-Atibba'. Rida, Nizar (pnyt.). Beirut: Dar Maktabah al-Hayah.

Ibn Hindu, 'Ali ibn al-Husayn. 2010. The key to Medicine and a Guide for Students. Miftah al-Tib wa Minhaj al-Tullab. Tibi, A. (Terj.). Qatar: Garnet Publishing.

Ibn al-Qifti, 'Ali ibn Yusuf. 1903. Tarikh al-Hukama'. Leipzig.

al-Kholy, S. A. 1984. The Function of Music in Islamic Culture. Egypt: General Egyptian Book Organization.

Oxford Dictionary of Sociology. 2000. Edisi ke-4. New York: Oxford University press.

Shehadi, F. 1995. Philosphies of Music in Medieval Islam. New York: E.J Brill.

Shiloah, A. 1995. Music in the World of Islam. A Socio-Cultural Study. Great Britain: Scolar Press.

The Cambridge Dictionary of Philosophy. 1999. Edisi ke-2. New York: Cambridge University Press.

The Concise Columbia Encyclopaedia. 1994. Edisi ke-3. New York: Columbia University Press.

The Dictionary of Philosophy. 1942. London: Vision Press.

Yusuf, Zakariya, (pnyt.). 1956. al-Shifa'. Kaherah: al-Matba' ah al-Amiriyyah.

Yusof, Zakariya. 1962. Musiqa al-Kindi. Baghdad: Matba'ah Shafiq. 